\title{
Urinary Neurotransmitter Metabolites in Drug-free Chronic Schizophrenic Patients Measured by Gas Chromatography Selected Positive Ion Monitoring
}

Edward F. Domino, $\S$ Benjamin N. Mathews and Sandra K. Tait

Department of Pharmacology, Lafayette Clinic, Detroit, Michigan 48207, USA and The University of Michigan, Ann Arbor, Michigan 48109, USA

\begin{abstract}
The free urinary metabolites, homovanillic, indoleacetic and 5-hydroxyindoleacetic acid were measured in $24 \mathrm{~h}$ urines obtained from seven highly selected drug-free chronic schizophrenic patients and seven mentally normal control subjects on a low amine diet. Gas chromatography selected ion monitoring of silylated extracts was used to assay each metabolite using its own deuterated form as an internal standard. In the electron impact mode the positive ion fragments used to quantitate the amount of each metabolite in the urine were, respectively, $\mathrm{m} / \mathrm{z}$ 209/211 for homovanillic acid, 319/321 for indoleacetic acid and 290/292 for 5-hydroxyindoleacetic acid. It was found essential that each compound be assayed using its own deuterated derivative as the internal standard. When expressed per mg creatinine, the homovanillic and 5-hydroxyindoleacetic acid levels of the chronic schizophrenic patients were in the normal range, but indoleacetic acid was slightly and statistically significantly higher, $p=0.01$.
\end{abstract}

\section{INTRODUCTION}

Urinary levels of neurotransmitter metabolites other than 4-hydroxy-3-methoxyphenylethyl glycol (HMPG) do not reflect brain metabolism. ${ }^{1}$ Nevertheless, some theories of schizophrenia suggest a gross abnormality in either dopamine or serotonin (5-hydroxyindolethylamine, 5-HT) metabolism which may be reflected in the urine. ${ }^{2-4}$ Numerous investigators have reported either an increase, decrease, or no change in each of these neurotransmitter metabolites in various schizophrenic patient populations. However, the patients studied were heterogenous, drug intake and diet not controlled, and relatively nonspecific chemical assays were used. ${ }^{5-9}$

The present research deals with a small group of highly selected, drug-free schizophrenic patients and normal subjects on a low amine diet in which urinary homovanillic acid (HVA), indoleacetic acid (IAA) and 5-hydroxyindoleacetic acid (5-HIAA) were assayed using gas chromatography and selected positive ion monitoring.

\section{EXPERIMENTAL}

\section{Subjects}

Seven normal male volunteers and seven male drug-free chronic schizophrenic patients were studied. No

† Supported in part by the Psychopharmacology Research Fund (Domino) and the Lafayette Clinic Schizophrenia Research Fund. Address reprint requests to: Reprint Secretary, Lafayette Clinic, 951 E. Lafayette, Detroit, Michigan 48207, USA.

₹ Abbreviations: $\mathrm{HMPG}=4$-hydroxy-3-methoxyphenylethyl glycol; $5-\mathrm{HT}=5$-hydroxyindolethylamine; $\mathrm{HVA}=$ homovanillic acid; IAA $=$ indoleacetic acid; 5-HIAA = 5-hydroxyindoleacetic acid

$\S$ Author to whom correspondence should be addressed: Lafayette Clinic, 951 E. Lafayette, Detroit, Michigan 48207, USA. significant differences were found between the two groups in age or height. However, the patients' mean weight was $66.4 \mathrm{~kg}$, while the controls' mean weight was $84.7 \mathrm{~kg},(p<0.025)$. The controls were all drug-free, Lafayette Clinic personnel. The patients had all been mentally ill since adolescence or early adulthood. No significant therapeutic benefits were derived from neuroleptic medication, so all drug administration had been discontinued for at least two years to avoid the risk of tardive dyskinesia.

The research protocol was approved by the Lafayette Clinic Institutional Review Board and the Technical Advisory Committee on Research of the Michigan Department of Mental Health.

\section{Diet}

The subjects were on a low amine diet ${ }^{10.11}$ and did not eat pineapples, walnuts, broadbeans, bananas, eggplant, tomatoes, tomato products, or 'aged' cheeses for one week before the collection. Alcohol was not permitted for three days before the collection period. These restrictions also applied during the $24 \mathrm{~h}$ of the collection. The patients were all given a vitamin supplement.

The urine was collected in plastic containers and kept at either $4{ }^{\circ} \mathrm{C}$ or $-20^{\circ} \mathrm{C}$ during the collection period. At the end of the collection period, the urines were stored at $-80^{\circ} \mathrm{C}$ until analysis.

\section{Chemical assays}

Urine creatinine was determined by a modification of the Jaffé reaction ${ }^{12}$ as well as a new high performance liquid chromatographic assay developed by Buchanan et $a l^{13}$ HVA, IAA, 5-HIAA were extracted by a 
modification of the anion exchange method of Jaakonmaki et $a l^{14}$ and further developed by other investigators. ${ }^{15,16}$ Our procedure closely follows that of Gates et al. ${ }^{17}$ The overall scheme is summarized in Fig. 1. The internal standard for IAA, 5-HIAA and HVA was the $\alpha-\left[{ }^{2} \mathrm{H}_{2}\right]$ analog (Merck \& Co., Inc., Rahway, New Jersey). A urine volume corresponding to $1.5 \mathrm{mg}$ of creatinine was used for analysis. This was added to a tube containing $8 \mu \mathrm{g}$ of each internal standard evaporated from a stock methanol solution. The urine was then treated with $3 \mathrm{ml}$ of $0.1 \mathrm{M}$ barium hydroxide and centrifuged to precipitate phosphate and sulfate as the barium salts. The precipitate was washed with $2 \times$ $1 \mathrm{ml}$ barium hydroxide and the solutions combined. Acetic acid was then used to neutralize the supernatants to a $\mathrm{pH} \mathrm{7-8.} \mathrm{This} \mathrm{avoided} \mathrm{the} \mathrm{formation} \mathrm{of} \mathrm{excess}$ pyridium hydrochloride in the final product. The organic acids were then isolated on a DEAE Sephadex column of $1 \mathrm{~cm}$ diameter filled to a height of $8 \mathrm{~cm}$ (A-25-120 DEAE Sephadex, Sigma Chemical Co., St Louis, Missouri).

The Sephadex was previously treated with $1.0 \mathrm{M}$ pyridium acetate for $48 \mathrm{~h}$ and a final equilibration at $0.5 \mathrm{M}$ pyridium acetate for another $24 \mathrm{~h}$. Several changes of each wash were made. Before use, the columns were rinsed with $20 \mathrm{ml}$ of $0.5 \mathrm{M}$ pyridium acetate. After the urine flowed through, the columns were rinsed with $50 \mathrm{ml}$ of distilled water. The isolated acid fraction of urine was then eluted from the columns with $40 \mathrm{ml}$ of $1.5 \mathrm{M}$ pyridium acetate. This solution was then freeze dried. The residue was derivatized with $130 \mu \mathrm{l}$ of bis-(trimethylsilyl)trifluoroacetamide (Pierce) and $30 \mu \mathrm{l}$ dimethylformamide as a catalyst, by heating for $30 \mathrm{~min}$ at $80^{\circ} \mathrm{C}$ to form the trimethylsilyl derivatives. Immediately after derivatization, the solution was transferred to glass capillary tubes and flame sealed. The tubes were then stored at $4{ }^{\circ} \mathrm{C}$ until analyzed by GCMS. All glass containers were silated before use with $5 \%$ dimethyldichlorosilane in toluene. Due to the light sensitivity of 5-HIAA, the columns and freeze dry flasks were shielded with aluminum foil. ${ }^{18}$

A Finnigan 3200 quadrapole gas chromatograph mass spectrometer with a 6100 data system was used in this study. GC conditions were with a helium carrier flow of about $20 \mathrm{ml} \mathrm{min}^{-1}$, injection port temperature of $250{ }^{\circ} \mathrm{C}$, and glass jet separator temperature at $220^{\circ} \mathrm{C}$. A $3 \%$ OV 225 on $100 / 120$ Gas Chrom Q (Applied Science) column, $5 \mathrm{ft} \times 2 \mathrm{~mm}$ i.d. was used.

The mass spectrometer was operated at $70 \mathrm{eV}$ in the electron impact mode. Mass fragmentography of HVA was done isothermally with the $\mathrm{GC}$ column at $170^{\circ} \mathrm{C}$. IAA and 5-HIAA were analyzed on a single GC run with data system control and change over for the proper ion fragments to be monitored. These were run with the $\mathrm{GC}$ column at $190^{\circ} \mathrm{C}$. Standard curves of each compound were prepared by spiking urine with increasing amounts of each compound.

\section{RESULTS}

The mass spectra of all three derivatized compounds and their deuterated analogs show characteristic fragmentation patterns (see Figs. 2-4) corresponding to

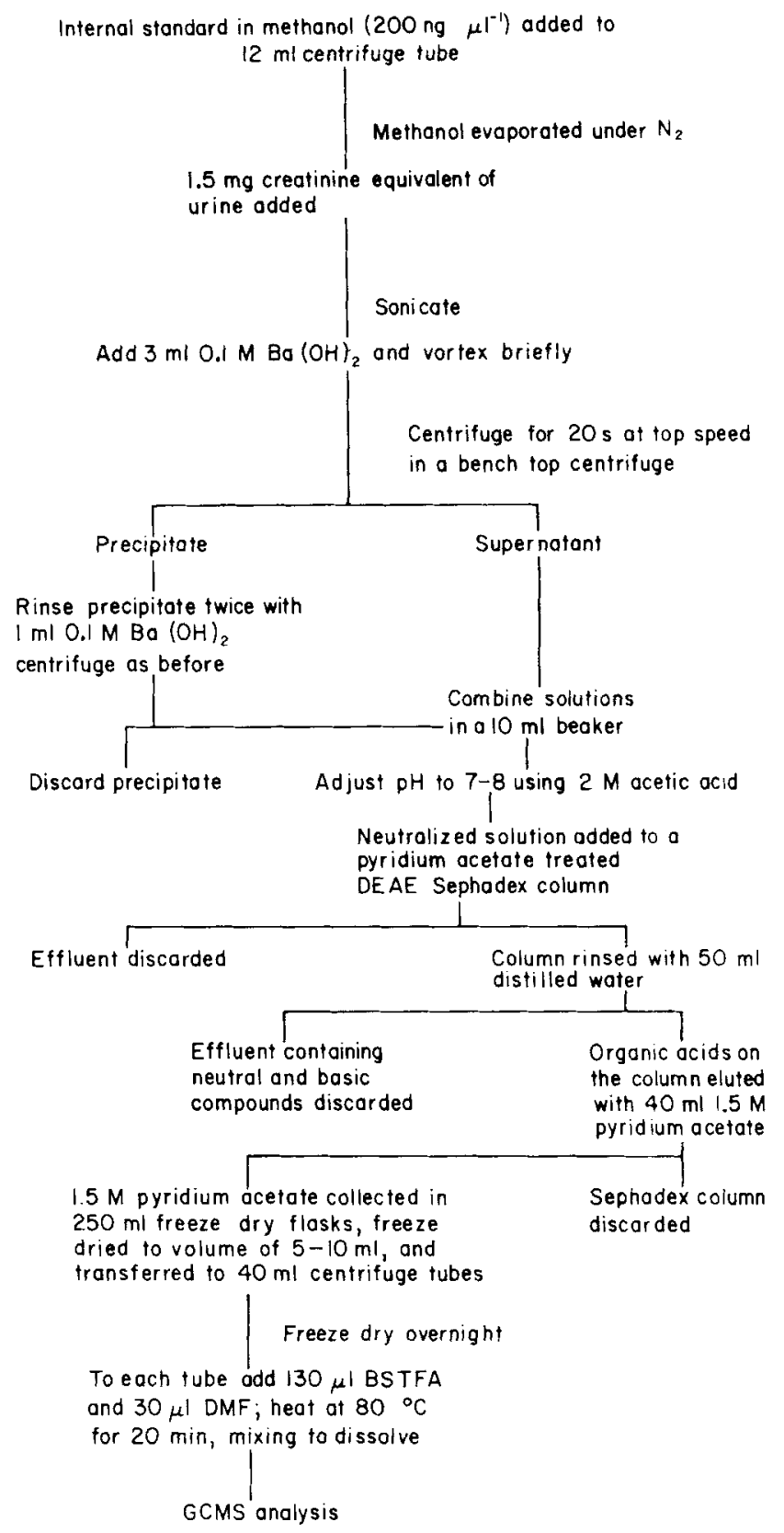

Figure 1. Method of extracting and derivatizing organic urine acid metabolites. This is a general method which is useful for all organic acids in the urine, not only those studied herein. Especially important is the use of a stable isotope derivative of HVA, 5-HIAA and especially IAA for quantitative and linear recoveries.

$\alpha$-cleavage as shown even with different derivatives. ${ }^{19,20}$ For each compound and its deuterated internal standard, the most prominent ion pair consistent with good selectivity from interfering peaks was used for quantification. Since in our Finnigan data system four ions could be monitored simultaneously in the selected ion monitoring mode, two other ions were monitored for each compound to insure specificity.

For HVA and $\alpha-\left[{ }^{2} \mathrm{H}_{2}\right] \mathrm{HVA}$, these ions were $m / z 209$ and 211 for quantification and the molecular ions at $\mathrm{m} / \mathrm{z}$ 326 and 328 were monitored to confirm.the identity of HVA. For IAA and $\left[{ }^{2} \mathrm{H}_{2}\right]$ IAA the prominent ions $\mathrm{m} / \mathrm{z}$ 202 and 204 showed minor interferences so quantification was done on the molecular ions 319 and 


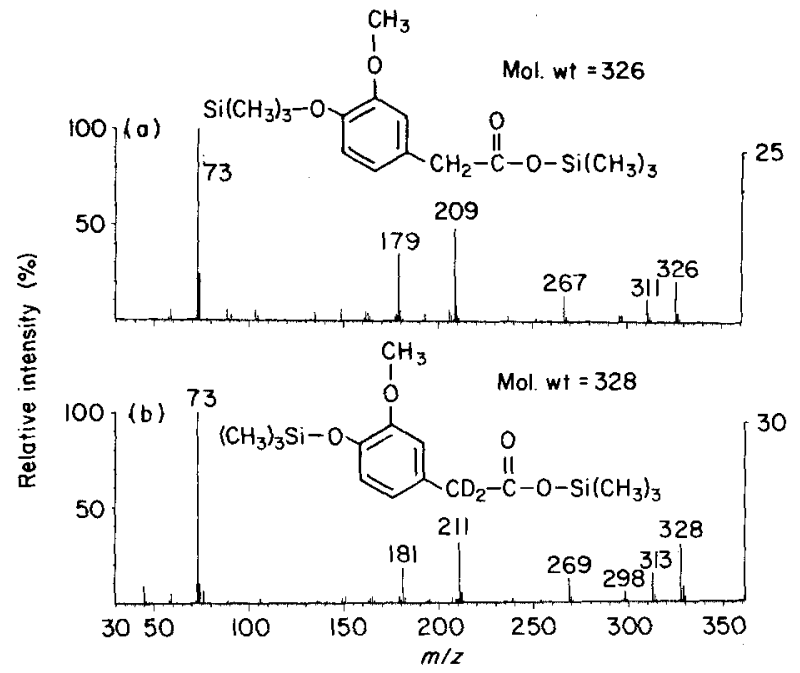

Figure 2. Mass spectra of homovanillic acid (a) and its $\alpha$-deuterated trimethylsilyl derivative (b). The ion at $m / z 209$ and the molecular ion at $m / z 326$ for HVA, and the corresponding ions at $m / z 211$ and 328 for $\alpha-\left[{ }^{2} \mathrm{H}_{2}\right]$-HVA TMS were monitored for positive identification.

321. For 5-HIAA and $\left[{ }^{2} \mathrm{H}_{2}\right]-5$-HIAA interferences were sometimes noted at the molecular ions at $\mathrm{m} / \mathrm{z} 407$ and 409 , so quantification was done at $\mathrm{m} / \mathrm{z} 290$ relative to 292 .

We experienced great difficulty in obtaining complete $24 \mathrm{~h}$ urine collections from our very ill, nonmedicated patients. We have included in our data only the urine collections which had a creatinine value of at least $14.0 \mathrm{mg} \mathrm{kg}^{-1} 24 \mathrm{~h}^{-1}$ and with a pH of 5.0-6.5. Using these criteria, we kept one to three collections from each subject and averaged each individual's results. The $24 \mathrm{~h}$ urinary volumes were still significantly lower $(p<$ 0.005 ), so we based our values on $\mathrm{mg}$ creatinine excreted.

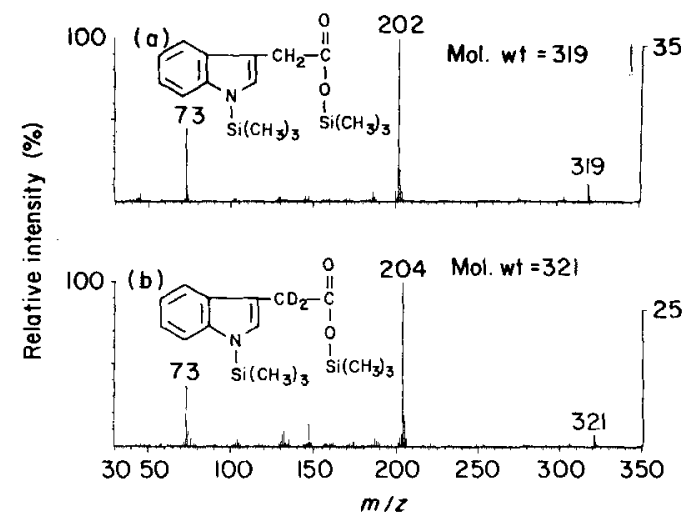

Figure 3. Mass spectra of indoleacetic acid (a) and its $\alpha$-deuterated trimethylsilyl derivative (b). The ion at $\mathrm{m} / \mathrm{z} 202$ and the molecular ion at $\mathrm{m} / z 319$ for IAA, and the corresponding ions at $m / z 204$ and 321 for $\alpha-\left[{ }^{2} H_{2}\right]-$ IAA TMS were monitored for positive identification.

Urinary 5-HIAA, IAA and HVA levels were within normal limits ${ }^{18,21-27}$ summarized in Table 1 . The patient IAA values were greater than those of the normal control subjects and were statistically significant $(p=$ 0.01 ). Both HVA and 5-HIAA urinary levels were not significantly different from those of the controls.

\section{DISCUSSION}

The disadvantage of the present assay is the length of time required to prepare samples prior to analysis. This is due to the preparation and column separationapproximately one working day-and the time required for freeze drying-about $24 \mathrm{~h}$ for 14 samples in our freeze drier (Virtis Model 10-010). The advantages are stability of the final samples and ease of applicability to

Table 1. Comparison of $\mathbf{2 4}$ hour urinary levels of homovanillic, indoleacetic and 5-hydroxyindoleacetic acid levels in drug-free chronic schizophrenic patients and mentally normal control subjects ${ }^{\mathrm{a}}$

\begin{tabular}{|c|c|c|c|c|c|c|c|}
\hline & $\begin{array}{l}\text { Weight } \\
(\mathrm{kg})\end{array}$ & $\begin{array}{c}\text { Body } \\
\text { surface } \\
\text { area }\end{array}$ & $\begin{array}{c}24 \mathrm{~h} \\
\text { volume }(\mathrm{ml})\end{array}$ & $\begin{array}{l}\text { Creatinine } \\
\left(\mathrm{mg} \mathrm{kg}^{-1}\right)\end{array}$ & $\begin{array}{c}\text { HVA } \\
\left(\mu \mathrm{gg}^{-1} \mathrm{C}\right)\end{array}$ & $\underset{\left(\mu \mathrm{g} \mathrm{mg}{ }^{-1} \mathrm{C}\right)}{(\mathrm{AA}}$ & $\begin{array}{c}\text { 5-HIAA } \\
\left(\mu \mathrm{g} \mathrm{mg}^{-1} \mathrm{C}\right)\end{array}$ \\
\hline \multicolumn{8}{|l|}{ Controls } \\
\hline 1 & 71.4 & 1.92 & 1381 & 20.31 & 8.23 & 8.61 & 5.39 \\
\hline 2 & 85.5 & 2.01 & 1320 & 21.31 & 6.22 & 6.96 & 4.40 \\
\hline 3 & 92.3 & 2.12 & 1633 & 20.2 & 5.06 & 8.57 & 5.64 \\
\hline 4 & 78.2 & 2.02 & 1577 & 21.78 & 6.23 & 7.60 & 3.94 \\
\hline 5 & 83.25 & 2.00 & 1340 & 28.17 & 4.72 & 5.47 & 6.03 \\
\hline 6 & 87.75 & 2.12 & 1150 & 21.1 & 5.23 & 6.48 & 3.88 \\
\hline 7 & 94.5 & 2.20 & 1000 & 33.65 & 3.60 & 5.64 & 4.84 \\
\hline Mean $\pm S E$ & $84.7 \pm 3.0$ & $2.06 \pm .04$ & $1343 \pm 84$ & $23.8 \pm 1.9$ & $5.61 \pm 0.55$ & $7.05 \pm 0.48$ & $4.87 \pm 0.32$ \\
\hline \multicolumn{8}{|l|}{ Patients } \\
\hline 1 & 70.9 & 1.87 & 500 & 14.53 & 5.00 & 8.72 & 5.49 \\
\hline 2 & 63.6 & 1.81 & 1185 & 25.3 & 2.98 & 7.93 & 4.16 \\
\hline 3 & 49.5 & 1.57 & 345 & 19.93 & 5.40 & 7.44 & 5.55 \\
\hline 4 & 65.5 & 1.81 & 819 & 22.5 & 5.05 & 9.78 & 5.45 \\
\hline 5 & 59.1 & 1.73 & 902 & 16.3 & 4.38 & 10.4 & 6.9 \\
\hline 6 & 100.0 & 2.28 & 1150 & 14.49 & 5.03 & 10.0 & 4.67 \\
\hline 7 & 56.2 & 1.75 & 351 & 17.17 & 5.01 & 8.68 & 5.29 \\
\hline Meant SE & $66.4 \pm 6.2$ & $1.83 \pm .08$ & $750 \pm 135$ & $18.6 \pm 1.6$ & $4.69 \pm 0.31$ & $8.99 \pm 0.42$ & $5.36 \pm 0.32$ \\
\hline Probability & 0.021 & 0.029 & 0.0028 & 0.060 & 0.172 & 0.010 & 0.306 \\
\hline
\end{tabular}




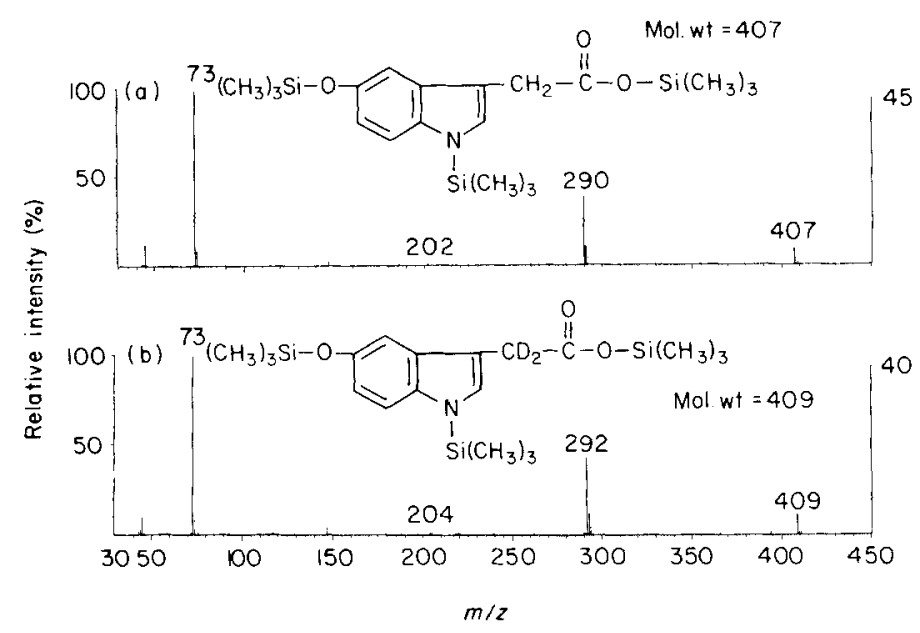

Figure 4. Mass spectra of 5-hydroxyindoleacetic acid (a) and its $\alpha$-deuterated trimethylsilyl derivative (b). The ion at $m / z 290$ and the molecular ion at $\mathrm{m} / \mathrm{z} 407$ for $5-\mathrm{HIAA}$, and the corresponding ion at $\mathrm{m} / z 292$ and 409 for $\alpha-\left[{ }^{2} \mathrm{H}_{2}\right]-5$-HIAA TMS were monitored for positive identification.

other organic acids. Hence, the assay is used primarily as a procedure for profiling all urine organic acids where it is essential to extract all acidic compounds equivalently. As such, this assay would be readily adaptable to any other organic acids of interest.

When stored in an ordinary refrigerator $\left(+4^{\circ} \mathrm{C}\right)$ we detected no deterioration of the derivatized samples for as long as a year. It must be noted, though, that the use of deuterated internal standards would mask minor deterioration of a compound. This stability is a definite advantage in laboratories with user shared GCMS systems, where equipment access might be delayed. The precision of this assay, when the corresponding deuterated acid is used as the internal standard, is satisfactory. Duplicate samples assayed independently were within $10 \%$ of each other. This was not the case when $\left[{ }^{2} \mathrm{H}_{2}\right]-5$-HIAA was used as the internal standard for IAA in particular. It should also be pointed out that there is a problem of cross-talk between the ${ }^{1} \mathrm{H}$ and ${ }^{2} \mathrm{H}$ compounds. There is a slight but real contribution of the deuterated internal standard to the masses monitored for the naturally occurring metabolites and vice versa. This varies with the specific compounds and their relative abundance. If the ratio of the stable isotope and naturally occurring species is within relatively narrow limits, the standard curve is linear. This is not true at the extremes. Although these relative contributions can be calculated, we derived standard curves and used the linear segments for our analyses.

It should be emphasized that the schizophrenic patients used in this study were highly selected as having chronic process schizophrenia, unresponsive to current antidopamine medication. Presumably they represent a subgroup of schizophrenics whose illness does not include a disturbance of dopamine metabolism. Urinary levels of HVA, the metabolite of dopamine, were normal. Although 5-HIAA levels tended to be slightly higher in these patients, the differences were not statistically significant. However, the elevated IAA urinary levels were significant even in this small sample size.

It should be noted that we measured only free levels of these organic acids. Further studies are needed to measure the relative amounts of free vs conjugated acid metabolites.

\section{Acknowledgements}

The authors would like to acknowledge the initial efforts of Dr John Matthews in this study and Dr Steven C. Gates whose advice regarding the assay techniques was most valuable.

\section{REFERENCES}

1. F. K. Goodwin and R. M. Post, Biology of the Major Psychoses: A Comparative Analysis, ed. by D. X. Freadman, p. 299. Raven Press, New York (1975).

2. R. J. Wyatt, B. A. Termini and J. Davis, Schizophr. Bull. 4, 10 (1971).

3. E. F. Domino, Neurotransmitter Balances Regulating Behavior, ed. by E. F. Domino and J. Davis, p. 185. NPP Press, P.O. Box 1491, Ann Arbor, Michigan (1975).

4. H. Y. Meltzer and S. M. Stahl, Schizophr. Bull. 2, 19 (1976).

5. E. H. LaBrosse, 1. J. Kopin, W. R. Felix Jr and R. J. Westlake, J. Psychiatr. Res. 2, 185 (1964).

6. S. Banerjee and P. S. Agarwal, Proc. Soc. Exp. Biol. Med. 97, 657 (1958).

7. G. A. Buscaino and L. Stefanachi, Acta Neurol. 12, 1188 (1957).

8. G. B. Leyton, Br. Med. J. 2 (5105), 1136 (1958).

9. J. M. Fragoso Mendes and J. A. Lopes do Rosario, Encephale 48, 501 (1959)

10. A. Barbeau and L. J. Wilkoff, Can. Med. Assoc. J. 80, 717 (1959).

11. S. Udenfriend, W. Lovenberg and A. Sjoerdsma, Arch. Biochem. Biophys. 85, 487 (1959).

12. J. D. Bauer, G. Toro and P. G. Ackerman, Bray's Clinical Laboratory Methods, 6th Edn, p. 65. C. V. Mosby Company, St Louis (1962).

13. D. N. Buchanan, S. Tait and E. F. Domino, J. Chromatogr. in press.

14. P. I. Jaakonmaki, K. L. Knox, E. C. Horning and M. G. Horning, Eur. J. Pharmacol. 1, 63 (1967).
15. R. A. Chalmers and R. W. E. Watts, Analyst 97, 958 (1972).

16. J. A. Thompson and S. P. Markey, Anal. Chem. 47, 1313 (1975).

17. S. C. Gates, N. Dendramis and C. C. Sweeley, Clin. Chem. 24 1674 (1978).

18. N. Fornstedt, Anal. Chem. 50, 1342 (1978).

19. J. Segura, F. Artigas, E. Martinez and C. Gelpi, Biomed. Mass Spectrom. 3, 91 (1976).

20. E. Änggård and G. Sedvall, Anal. Chem. 41, 1250 (1969).

21. C. M. Williams and C. C. Sweeley, Biomedical Applications of Gas Chromatography, ed. by H. A. Szymanski, p. 225. Plenum Press, New York (1964)

22. B. J. Haverback, A. Sjoerdsma and L. L. Terry, N. Engl. J. Med. 255, 270 (1956).

23. S. Takahashi, M. Yoshioka, S. Yoshive and Z. Tamura, J Chromatogr. 145, 1 (1978).

24. C. R. J. Ruthven and M. Sandler, Anal. Biochem. 8, 282 (1964)

25. K. N. F. Shaw, A. McMillan and M. D. Armstrong, J. Biol. Chem. 226, 255 (1957).

26. F. S. Messiha, E. Bakutis and V. Frankos, Clin. Chim. Acta 45 159 (1973).

27. C. M. Williams and C. C. Sweeley, J. Chin. Endocrinol. Metab. 21, 1500 (1961).

Received 1 February 1979

(C) Heyden \& Son Ltd, 1979 